\title{
Pivotal role of intensivist despite low staffing
}

\author{
AM Burki ${ }^{*}$, L Noor ${ }^{2}$, N Ali $^{3}$ \\ From ESICM LIVES 2015 \\ Berlin, Germany. 3-7 October 2015
}

Appointment of an intensivist to the nursing staff for better patient outcome with low level of nursing care has not been challenged before in studies. An intensivist not only gives plan for the patient management but also can educate the nursing staff for better patient outcome.

\section{Objectives}

The purpose of this study is to establish the effect of appointing an intensivist to low nursing staff on ICU mortality.

\section{Methods}

This retrospective observational study is conducted in intensive care unit of combined military hospital Peshawar. Total of 2041 patients are included in this study during a period from 2011 to 2014. Only those patients were included in the study who were 12 years or older, those who require organ support and had ICU stay for at least 24 hours . Patients with advanced disease who require palliative care only, those who require CABG were excluded from the study.

Data is collected from admission and discharge book maintained at ICU. Patients are divided in two groups: group A includes patients who received nursing care without an intensivist and group B includes patients who received nursing care under supervision of an intensivist.

\section{Results}

Of total 2041 patients 54\% were men.The mean age was 58 years. Each group has patients with medical and surgical ailments.Outcome is measured interms of mortality. Mortality in group A is 23.01 to $33.02 \%$ and in group B is 20.29 to $23.60 \%$ that is statistically significant and support our hypothesis that appointment of intensivist to nursing staff is associated with low mortality and better patients outcome,despite of low human resource.

\section{Conclusions}

In our retrospective cross sectional study addition of an intensivist to the nursing staff has improved the mortality rate to about 20.29 to $23.60 \%$ which is comparable to the international values 11 to $18 \%$.

\section{Grant Acknowledgment}

Professor Nadir Ali

Dr Lubna Noor

\section{Authors' details}

${ }^{1}$ Combined Military Hospital Peshawar, Anaesthesia and Intensive Care, Peshawar, Pakistan. ${ }^{2}$ Combined Military Hospital Peshawar, Obs \& Gynae, Peshawar, Pakistan. ${ }^{3}$ Combined Military Hospital Peshawar, Pathology, Peshawar, Pakistan.

Published: 1 October 2015

\section{References}

1. Needleman J, Buerhaus P, Mattke S, Stewart M, Zelevinsky K: Nurse-staffing levels and the quality of care in hospitals. N Engl J Med 2002, 346:1715-1722.

2. Aiken LH, Clarke SP, Sloane DM, Sochalski J, Silber JH: Hospital nurse staffing and patient mortality, nurse burnout, and job dissatisfaction. JAMA 2002, 288:1987-1993.

3. Mark BA, Harless DW, McCue M, Xu Y: A longitudinal examination of hospital registered nurse staffing and quality of care. Health Serv Res 2004, 39:279-300, [Erratum, Health Serv Res 2004;39:1629.].

4. Sales A, Sharp N, Li Y-F, et al: The association between nursing factors and patient mortality in the Veterans Health Administration: the view from the nursing unit level. Med Care 2008, 46:938-945.

doi:10.1186/2197-425X-3-S1-A868

Cite this article as: Burki et al:: Pivotal role of intensivist despite low staffing. Intensive Care Medicine Experimental 2015 3(Suppl 1):A868. 